\title{
Multimodal Application for IT English Teaching with the Use of Three-Dimensional Textbook
}

\author{
Xian-jing SHI \\ Suzhou Industrial Park Institute of Services Outsourcing, Suzhou, Jiangsu, China
}

Keywords: Multimodal; E-Book; Online Learning Platform; IT English.

\begin{abstract}
The aim of this paper is to discuss multimodal features of three-dimensional IT English textbook which includes audiovisual resources, an E-book and an online learning platform. And the paper also focuses on multimodal teaching practice in IT English course. IT English lecture which integrates pictures, text, animations, videos and audios can facilitate students' auditory, visual, tactile and other senses. By this means, the effect of English teaching will be greatly improved.
\end{abstract}

\section{Introduction}

Over the last few decades, the advanced educational technology brought significant changes in educational concepts. Previously, students depended on classroom attendance and books to gain knowledge. Obviously, this traditional learning mode can no longer satisfy students' personal needs. The rapid development of modern information technology has made the acquisition, update and accumulation of students' knowledge more diversified and made the application of multimodal approaches feasible.

Multimodality in today's classrooms refers to 'multiple' modes of representation, with combined elements of print, visual images and design [1]. In recent years, textbooks have undergone rapid changes in China, which includes the transitional changes from traditional paper textbooks to textbooks with audio and video discs, to the emergence of three-dimensional textbooks which include electronic, audiovisual resources and network systems. Three-dimensional textbooks make English teaching possible in multimodality. Teachers can take advantages of visual, verbal, written, gestural and musical resources in lectures to mobilize the coordination operation of the auditory, visual and tactile senses. For English learners, English learning can be made more intuitive, engaging and interactive. By mobilizing learners' multiple senses, memory can be improved, understanding can be enhanced, and learners can be motivated. Multimodal approaches have the potential to enhance the effectiveness of English learning.

\section{Literature Review}

Multimodality refers to the combination of different semiotic modes in a finished communication or communication activities. Semiotic modes are these different systems for meaning-making or possible "channels" such as speech, writing, images, etc. Semiotic modes can include visual, verbal, written, gestural and musical resources for communication. They also include various "multimodal" ensembles of any of these modes [2]. This theory holds that the traditional paralinguistic images, colors, music and action symbols are no longer in the auxiliary position in modern social communication, but form a broader semiotic resources along with text symbols to make meaning [3].

The analysis and application of multimodality in teaching is one of the major topics of discussion in America as well as Europe. In this field, the earliest researcher is R. Barthes, who discussed the interaction between image and language in his article Rhetoric of the Image in 1977. Kress and Van Leeuswen's research built the foundation of multi-modality study. In their book, Reading Images of 1996, they held that images should be studied in terms of Halliday's approach because of its social semiotic feature [4]. New London Group was the first applying multimodality to language teaching. They thought the training of the students' multi-literacy was the main task of language teaching [5]. From then on, the researches interested in multimodality and language teaching became prevalent. 
In the modern era, advance in information technology makes multimodality possible in different schools, and the multimodal teaching approaches are popularized among an increasing number of English teachers. The text-mode teaching in traditional language teaching ignores the fact that paralinguistic images, colors, music and action symbols along with text symbols form broader semiotic resources in meaning construction. Multimodal teaching advocates that teachers should take advantage of more channels and more teaching methods such as websites, pictures, role-plays, etc., to mobilize students' multiple senses engaging in language teaching [6].The text-mode teaching is no longer suitable for a society in which information technology is highly developed. Teachers are able to take advantage of multimedia resources and tools in the teaching environment. These resources and tools may include for example, interactive videos and images, recorded lecture presentations, online quizzes, discussion forums (synchronous and asynchronous), visual representations of student data to depict progress and on what the student is doing to learn [7]. Different presentation modes are used to attract students' different sensory modalities (visual, auditory and tactile). A variety of sensory collaboration can improve students' understanding and enhance their internalization of knowledge.

\section{Multimodal Features of IT English Textbook}

Multimodal teaching based on three-dimensional textbooks is feasible in the society where information technology is an indispensable part of foreign language education. Three-dimensional textbook focuses on the input and interaction of information, and the static teaching content is transformed into a dynamic form which integrates picture, text, sound, video and other resources. Three-dimensional textbook incorporates multimedia technology that allows instructional elements to be presented in more than one sensory mode. It can mobilize students' multiple senses and facilitate the interaction between teachers and students. Mayer argues that student's learning becomes more meaningful when an array of interactive tools and resources are deployed rather using text alone [8].

Make IT Easy: An Advanced English Course for Information Technology Majors published by Shanghai Foreign Language Education Press is a three-dimensional textbook which includes student book, teacher's manual, e-book, and online learning platform. The teaching content directly comes from IT enterprises, making the book more true to life. The three-dimensional textbook supplemented by an E-book and an online learning platform is full of multimedia resources. It enables students to better understand language and improve their cross-cultural communication skills.

Each unit is based on the process of IT product development and some related topics of the IT business. The five main characters from White Company and Peterson Company appear frequently in the entire textbook. It involves various workplace scenarios in the IT industry. Each unit is equipped with rich audiovisual resources relevant to the topic.

The features of this textbook are as follows:

\subsection{Three-dimensional}

The three-dimensional textbook contains text, pictures, videos and network information related to the theme. The student book is mainly used for classroom teaching and the teacher's manual for teachers' reference. They contain text, pictures or diagrams. The online learning platform has the following functions, such as audio and video playback, text reading, online test, announcement, teacher-student interaction, etc. It is possible for teachers to track students' study pace and offer feedback. This will greatly improve students' motivation. In addition, it can also synchronize data with e-books and improve the effect of English learning. After class, students can have access to the online learning platform for self-learning with mobile devices such as tablet PC and cellphone. Teachers can post notices, assignments, articles and videos on the online learning platform. Students are required to complete the tasks according to teachers' requirements. The e-book is student book publication made available in digital form, consisting of texts, images, exercises, audios and videos. Different from the student book is that the e-book has much more supplementary reading and 
listening sections in digital form. The application of e-book avoids the weaknesses of traditional English textbooks, mediating the shift from the print-based education into multimodal education.

\subsection{Informational}

With the development of information technology, the spread of knowledge is no longer limited by time and place. English learning is no longer confined to classroom attendance. It is possible for students learn English even after class. Broad network and wireless network technology can enhance information dissemination, making it easier to consolidate students' knowledge and broaden their horizon. The content in this print-based student book can be supplemented by the resources in the online learning platform and e-book. Text, diagrams, pictures, audios, videos and other resources are provided, which is able to stimulate English language learning in meaningful ways. Multimodal resources on the online learning platform can be updated and enriched from time to time.

\subsection{Autonomous}

As important components of the textbook, the online learning platform and e-book serve as good resources and tools for students to learn independently. The e-book has a friendly interface and powerful functions. Students are able to make use of the e-book to review texts, audios or videos wherever and whenever they are so as to consolidate the content learned in the classroom. Students can make notes on it or highlight key sentences. It is made possible for them to finish exercises on the e-book and upload them for teachers' feedback. With the popularity of smart phones and iPad, students can enjoy easy access to the resources of the online learning platform in their spare time. There is an increasing body of evidence, which suggests that multimodality in learning is an active, student-centered approach in which students select the resources mostly relevant to them [8]. They autonomously plan their learning content, learning style and presentation of knowledge. They may choose to learn at their own pace. The online learning platform has detailed records of the time, pace and frequency of students' autonomous learning, which will serve as an incentive for students. The multimedia resources are more vivid, intuitive and attractive, which enables the students to take the initiative to learn.

\section{Multimodal Teaching Practice of IT English Course}

In the researcher's college, the above-mentioned IT English book is intended for second-year vocational students specializing in software technology. Their learning initiative is still relatively poor. Most of them are not interested in text-mode teaching at all. Multimodal educational and pedagogical approaches can greatly motivate them, arousing their passion for English learning. With the help of the three-dimensional textbook, traditional English class can be transformed from teacher-centered lectures to student-centered ones. In IT English class, teaching is mainly based on three modes, namely, text mode, image mode and sound mode. Various modes are interacting and interplaying in the process. Bezemer and Kress, two scholars on multimodality and semiotics, argue that students understand information differently when text is delivered in conjunction with a secondary medium, such as image or sound, than when it is presented in alphanumeric format only [9].

We will take a unit entitled Success on the Job for example to present multimodal teaching practice of IT English course.

\subsection{Text Mode}

Text mode plays the leading role in the teaching process. Before class, teachers set tasks for students on the online learning platform, and ask students to think about how to fit in on their first day of work. Students are required to read pre-class articles in the e-book. The articles are presented in text mode. They can learn autonomously so as to understand the cultural background, business scenarios and basic language expressions of the unit. During class, teachers can use PPT courseware to display an email from Peterson Company, a prestigious software company. The new employee 
John is informed to report for enrollment and join a staff training program from July 5 to July 7 . All these are presented in text mode, because only text mode can provide detailed information on tips and format for email-writing. Office etiquette, workplace guidelines, tips for new employees and some important words and expressions in the textbook are all presented in text mode. Teachers generally use text to express important information, supplemented by vivid pictures, diagrams, different fonts or colors, videos, etc.

After-class reading is also presented in text symbols. Students will be required to read supplementary materials on the online learning platform and e-book. The online learning platform has the function for online test. Test result can be recorded, analyzed and evaluated for checking learning effect. Moreover, teachers will require students to write an email to reply to the email from Peterson Company, which is also based on text mode.

\subsection{Image Mode}

The image mode is able to visualize abstract text symbols, making them more intuitive and vivid. The visual representation of content is important for clarifying subject matter and facilitating language learners' understanding. In this unit, new employee John makes some mistakes because of his ignorance of workplace etiquette, for example, lack of attention to his appearance, unpunctuality, excessive disruptive personal phone calls. The mistakes are displayed in vivid pictures on ppt courseware. This task is intended for group discussion. Afterwards, a video related to workplace guidelines is presented. The pictures and videos mentioned above can be included in the category of image mode. In image-based PPT courseware and videos, image is the main mode, while text mode and sound mode is in the auxiliary position. Moreover, students are asked to participate in such classroom activities as role play and presentation, making oral practice with both verbal and nonverbal language. Role play also belongs to the category of image mode which is supplemented by sound mode to create a dynamic atmosphere.

\subsection{Sound Mode}

Sound mode is available in courseware, audios, videos, etc. In videos, the sound mode is synchronic, which makes the image mode vivid. It is a guarantee for the audience to clearly understand the content in the video. In the process, students' sense organs are actively motivated, especially their visual and auditory senses. The textbook aims at developing the learner's listening and speaking skills through audio or video resources related to the unit theme. By motivating visual and auditory senses, learning effect will be certainly improved

\section{Conclusion}

In the contemporary society, computer networks, e-books, and multimedia courseware are constantly being applied in English teaching. Increasingly, multimodal teaching mode is becoming popularized. The world has witnessed the transitional shift from print-based education to multimodal education. Multimodal educational and pedagogical approach has a variety of advantages. It brings great reform in traditional teaching concept; it mediates the shift from student-centered lectures to teacher-centered lectures; it facilitates English learners' understanding and stimulates their motivation. As some scholars have pointed out, multimodal educational and pedagogical approach promotes the teaching through the means and principles of ICT education, e-learning and modern technology [10]. With various multimodal ensembles of verbal, visual, auditory, gestural resources, the three-dimensional textbook proves to be effective in IT English learning. When interactive tools and multimedia resources are presented instead of using text alone, student's learning is sure to become more meaningful and education effect is bound to be significantly improved.

\section{References}

[1] Jewitt, C., Multimodality and literacy in school classrooms [J]. Review of research in education, 
2008, 32 (1): 241-267.

[2] Kress, G. R., \& van Leeuwen, T. Multimodal discourse: The modes and media of contemporary communication [M]. London: Edward Arnold, 2001.

[3] Yun ZHANG, Computer Network-assisted Multimode Teaching in British and American Literature [J]. Computer-assisted Foreign Language Education, 2012, 3 (144): 65-67.

[4] Kress. G and Van Leweuwen. T, Multi-modal Discourse: the Modes and Media of contemporary communication [M]. London: Arnold, 2001.

[5] New London Group, A Pedagogy of Multiliteracies: Designing social Futures [J]. Harvard Educational Review, 1996.

[6] Xucai LIU, Computer Network-based Multimodal Teaching of British and American Literature [J]. International Journal of Computer Science. 2013, 10 (1): 19-24.

[7] Sharples, M. et al., Innovating Pedagogy 2016: Open University Innovation Report 5, Milton Keynes: Open University, 2016.

[8] Mayer, R. E., Multimedia learning [M]. New York: Cambridge University Press, 2001.

[9] Bezemer, Jeff; Gunther Kress. Writing in Multimodal Texts: A Social Semiotic Account of Designs for Learning [J]. Written Communication, 2008, 25 (2): 166-195.

[10] P.Kanari,G. Potamias, Mutlimodal teaching through ICT education: An e-twinning program as a case study of intercultural exchange [J]. 4th International Conference of Education, Research and Innovations, 2011, pp. 2805-2810. 